\title{
Gradients and the Specification of Planar Polarity in the Insect Cuticle
}

\author{
David Strutt \\ MRC Centre for Developmental and Biomedical Genetics and Department of Biomedical Science, \\ University of Sheffield, Sheffield, United Kingdom, S10 2TN \\ Correspondence: d.strutt@sheffield.ac.uk
}

In addition to specifying cell fate, there is a wealth of evidence that molecular gradients are also primarily responsible for specifying cell polarity, particularly in the plane of epithelial sheets ("planar polarity"). The first compelling evidence of a role for gradients in specifying planar polarity came from transplantation experiments in the insect cuticle. More recent molecular genetic analyses in the fruit fly Drosophila have begun to give insights into the molecular nature of the gradients involved, and how they are interpreted at the cellular level.

D evelopment requires the coordinated specification of at least three attributes: cell fate, tissue size, and cell polarity. In both theory and practice, all three can be specified by the action of gradients. This article examines the experimental evidence for gradients acting to specify cell polarity in developing tissues, considers the mechanisms by which they are thought to act, and discusses what remains unknown. The problem of how cell polarity is specified in the plane of a tissue ("planar polarity") is addressed. The tissues discussed are all formed from epithelial sheets that also show apicobasal cell polarity.

For more than half a century, the preeminent system for studying the regulation of planar polarity in epithelia has been the insect cuticle. This lends itself to the study of the problem by virtue of often being adorned by structures such as hairs, scales, ridges, or other protrusions that reveal the polarity of the underlying cells. However, the lack of polarized structures on the surface of other epithelialderived tissues should not be taken as evidence that the cells are not planar polarized, because often such polarity is cryptically expressed and only becomes apparent when the cells participate in a polarized process, such as cell division or cell intercalation.

\section{THE AGE OF TRANSPLANTATION}

Before the advent of the tools of modern molecular genetics, the key findings regarding mechanisms of cell polarization in the insect cuticle relied on the classical technique of tissue transplantation (also referred to as grafting). The power of this approach is evident in that these findings still form the basis for our current understanding of how cell polarity is specified and coordinated in epithelia.

Editors: James Briscoe, Peter Lawrence, and Jean-Paul Vincent

Additional Perspectives on Generation and Interpretation of Morphogen Gradients available at www.cshperspectives.org

Copyright (C) 2009 Cold Spring Harbor Laboratory Press; all rights reserved; doi: 10.1101/cshperspect.a000489

Cite this article as Cold Spring Harb Perspect Biol 2009;1:a000489 
D. Strutt

Probably the first important finding concerning how cells acquire their polarity was made by Piepho (1955), who observed that cells do not simply adopt a specific polarity at a particular point in development and subsequently maintain this polarity, but rather that the polarity that cells ultimately manifest is influenced by that of their neighbors. The critical experiment involved the $180^{\circ}$ rotation of a piece of larval cuticle in the moth Galleria before the stage at which polarized scales are produced, followed by culturing the animal to adulthood. Similar experiments had previously been performed by Wigglesworth in the bloodsucking insect Rhodnius (Wigglesworth 1940), and it had been noted that the grafted tissue produced a $180^{\circ}$ rotated cuticular pattern in the adult. This was also true for tissue in the center of Piepho's grafts; however, he noted that tissue at the edges of the graft, and the neighboring unrotated tissue, showed an intermediate pattern of polarity of the surface scales (Fig. 1A). Thus, although cells evidently had a correctly specified polarity at the time of grafting, this polarity was labile and subject to influence by the local environment.

A potential explanation for the results of Piepho was provided soon afterwards by Locke, who first proposed that cell polarities might be under the control of gradients (Locke 1959). Working on Rhodnius, Locke performed a series of elegant transplantation experiments designed to uncover how the pattern of laterally running ripples on the adult abdomen was specified. Like Piepho, he found that $180^{\circ}$ rotations caused the ripples around the clone boundaries to adopt intermediate orientations (Fig. 1B). To investigate the origin of this pattern, unrotated squares of cuticle were transplanted to various different positions within or between segments. Transplants which were moved to an equivalent anteroposterior (AP) position in a different segment, or to a different mediolateral position within the same segment, showed no change in the pattern of ridges. However, transplantation to a different AP position within a segment produced distinctive whorls in the ridges (Fig. 1D). On the basis of these data, Locke proposed that cells in different AP positions (or "levels") within a segment were incompatible with each other, and following transplantation, the pattern was altered to attempt to bring together cells of the same level. Most importantly, he introduced the concept of a segmentally repeating gradient in the cells of the epidermis, which provided them with information regarding their level.

The concept of a segmentally repeating gradient was further refined by Lawrence (1966) and Stumpf (1966) on the basis both of Locke's results and further experiments. They both proposed that the most likely form of the gradient was a diffusible substance, and on the basis of this, presented models that explained the polarity patterns seen following experimental manipulation (Fig. 1C,E). Lawrence also introduced the important concept that cells should be able to maintain the concentration of the gradient themselves to explain the stability of the polarity patterns observed. Further work, including computer modeling, further refined this idea, showing that a gradient model in which the diffusible substance was simply produced by a band of "source" cells at one end of the segment, could not adequately explain the experimental data. Instead, it was necessary to assume that each cell attempts to maintain its position in the gradient by acting as both source and sink for the gradient substance, but eventually becomes reset to the local concentration of the gradient (Lawrence et al. 1972).

Additionally, parallel experiments showed that the determination of cell fate within the segment was also consistent with pattern being specified by a repeating segmental gradient (Marcus 1962; Stumpf 1968). Together, this led to the model that a single gradient in the segment determined both cell fate and cell polarity, fate being specified according to the level or "scalar" of the gradient, and polarity being determined by the direction of slope or "vector".

An alternative proposal to the gradient being composed of a diffusible substance came from the work of Nardi and Kafatos (1976a,b), who instead suggested that polarity changes seen in grafts made in the wing of the moth Manduca could be better explained by a 


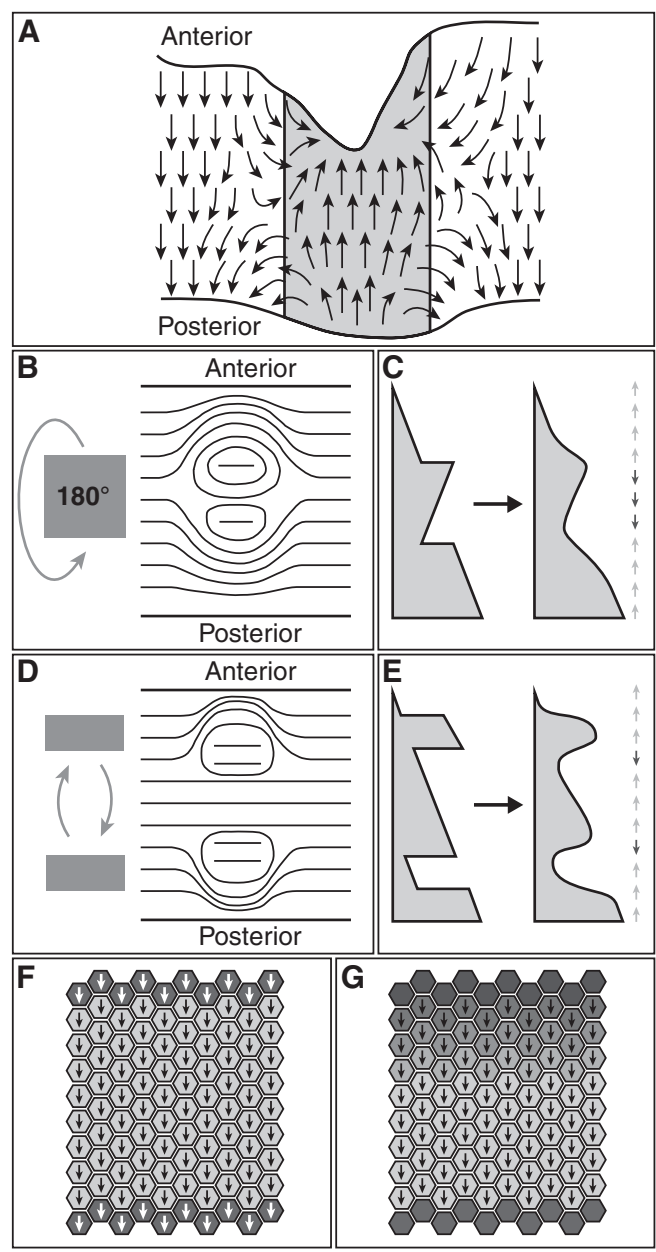

the segment boundary might generate a local gradient that polarizes the first few rows of cells, with polarity in the rest of the segment being again determined by local cell-cell interactions $(G)$.

gradient of adhesion across the axis of the tissue. Other work also supported the view that there were segmentally repeating gradients of cell affinity in insects (Nübler-Jung 1977; Wright and Lawrence 1981).

Working with the cotton bug Dysdercus, Nübler-Jung went on to explore the effects of differential adhesion on polarity patterns (Nübler-Jung and Grau 1987; Nübler-Jung and Mardini 1990). She concluded that whereas changes in cell fates following grafting could be explained by a gradient model, cell polarities were independently controlled, and that the polarity patterns seen after grafting were the result of juxtaposing cells with differing levels
Gradients and the Specification of Planar Polarity

Figure 1. Transplantation experiments and planar polarity in the insect cuticle. (A) Diagram showing the polarity changes observed in the cuticle of the moth Galleria following $180^{\circ}$ rotation of a piece of cuticle. Arrows indicate normal direction of polarization of scales from anterior to posterior. The gray box indicates approximate extent of the region of the cuticle that was rotated. (Based on Piepho 1955). ( $B, D)$ Diagrams showing the effects on the cuticle ridge pattern on Rhodnius, produced by rotating a piece of cuticle $180^{\circ}(B)$ or reciprocally transplanting pieces of cuticle to different positions in the AP axis of a segment $(D)$. Locke proposed that cells at different positions in the AP axis attempt to join up with cells of their original "level" after transplantation (Locke 1959). (C, E) Models based on the concept of a gradient of a diffusible substance specifying planar polarity (Lawrence 1966; Stumpf 1966) to explain the transplantation results of Locke. After transplantation, the gradient profile is altered. Diffusion then modifies the shape of the gradient to provide smooth peaks and troughs. Cells take on their polarity according to the direction of the slope of the gradient (arrows), with the experimental manipulations resulting in reversal of the slope and hence of polarity (dark gray arrows). ( $F, G)$ Models for how local cell alignment and the local organizing properties of segment boundaries might specify planar polarity across an insect segment. Cells within the segment (light gray) align their polarities with their immediate neighbors. Cells at the segment boundary (dark gray) might directly polarize the first row of cells in the segment (white arrows, $F$ ), with this polarity being passed on cell by cell. Alternatively, cells at

of adhesion. Although not excluding that initial polarities might be specified by a gradient, Nübler-Jung also presented an alternative model for how planar polarity might be determined in the insect segment. She observed that upon colchicine treatment, cells could polarize independently of the axis of the tissue, and thus that they were not absolutely dependent on an extrinsic polarity cue such as that provided by a gradient (Nübler-Jung 1987a), but that there was a strong preference for epidermal cells to arrange themselves in parallel arrays with common orientation (Nübler-Jung 1987b). On this basis, it was proposed that cells were locally constrained to adopt the 
D. Strutt

same polarity as their neighbors, possibly through the agency of the polarized distribution of cell surface molecules, and globally constrained by the segmental boundaries that acted to align the neighboring cells along the AP boundary (Nübler-Jung 1987b) (Fig. 1F).

Some caution must be exercised in comparing and interpreting the results of the different grafting experiments that underpin the work described above. The grafts were performed in a variety of different insects and tissues, and at varying stages of development. Thus, apparent differences in results that led to different models being proposed may simply indicate that more than one mechanism operates to specify planar polarity, with different mechanisms being dominant at different stages of development or in different contexts. Nevertheless, the following general principles emerge:

1. Polarity is strongly influenced by local interactions, such that cells attempt to adopt the same polarity as their neighbors. Such local coordination of polarity could be explained either by cells locally influencing the concentration of a graded substance, or by contact-mediated interactions between cells. A corollary of this is that polarity is a stable property of cells, which is only gradually altered by changes in the environment.

2. In normal development, polarity is intrinsically linked to cell fate, such that most likely the same system of positional information serves to set up both properties. In the simplest model, there is a single morphogenetic gradient, the scalar of which specifies cell fate and the vector cell polarity. However, in practice, neither the initial specification of cell polarity nor its subsequent maintenance may be directly dependent on the morphogenetic gradient. Instead, the gradient might specify boundaries of cell fates (such as the segmental boundaries of insects) that locally organize the polarity of neighboring cells, which is then propagated through the tissue by a cell-cell relay mechanism. The local organizing ability of boundaries might itself be mediated via local gradients, or by cell-cell contacts (Fig. 1F,G).
The insect experimental systems discussed thus far lack both the molecular and genetic tools that would permit further dissection of the mechanisms at work. Additionally, the transplantation methodology suffers from the major drawback that the grafted tissue often differs from the surrounding host in multiple different characters, such as cell fate, adhesion, and polarity, which greatly confounds the interpretation of the outcome. For these reasons, the focus of research has moved to Drosophila.

\section{THE RISE OF DROSOPHILA}

The last 20 years have seen great progress in understanding the role of gradients in specifying planar polarity through genetic and molecular analysis in the fruit fly. Nevertheless, the picture is still far from clear. Key questions, for which we have only partial answers, include: In which contexts are gradients directly involved in specifying cell polarities? Are such gradients formed from diffusible substances, or molecules tethered to either the cell surface or substrate, that vary in either concentration or activity? What are the relative contributions of gradients and cell-cell relays to local coordination of polarity? To what extent do boundaries act to organize cell polarity, and how do they do this?

The first systematic analysis of gene activities required for determination of planar polarity in Drosophila was that of Gubb and García-Bellido (1982). Notably, in genetic mosaics, they observed that although some of the loci analyzed acted cell autonomously to permit cells to express appropriate polarity, other loci had a nonautonomous effect, with both mutant cells and a few rows of neighboring nonmutant cells expressing incorrect polarity. This suggested a role for short-range cell-cell interactions in the determination of polarity in the Drosophila cuticle, similar to that indicated by grafting experiments in other insects. A further study of the frizzled $(f z)$ locus (Vinson and Adler 1987) showed that mosaic clones of cells lacking $f z$ activity in the wing exhibited directional nonautonomy such that hairs distal (but not proximal) to the clone were mispolarized (Fig. 2A). On this basis, it 
was proposed that $f z$ was involved in the transmission and/or generation of a polarity signal in the proximodistal (PD) axis of the wing.

The cloning of $f z$ revealed that it encoded a seven-pass transmembrane receptor (Vinson et al. 1989), and subsequent work showed that it was uniformly expressed across the PD axis of the wing and that such uniform expression was sufficient for its activity in planar polarity (Krasnow and Adler 1994; Park et al. 1994a,b). Furthermore, mosaic analysis in the eye showed that $f z$ also exhibited directional nonautonomy in this tissue, with clusters of photoreceptors (the ommatidial units that make up the eye) having inverted dorsoventral (DV) polarity on the polar side of clones (Fig. 2B) (Zheng et al. 1995).

Based on these findings, two models were proposed to explain the role of the Fz protein in locally controlling cell polarity. The first built on the gradient models of Lawrence and Stumpf (Lawrence 1966; Stumpf 1966; Lawrence et al. 1972) and proposed that Fz was involved in the maintenance of a gradient of a locally acting nonautonomous polarity signal (Fig. 2C) (Adler et al. 1990, 1997; Zheng et al. 1995). The second model envisaged $\mathrm{Fz}$ being involved in a cell-cell relay, passing a directionally biased signal from cell to cell (Vinson et al. 1989; Adler et al. 1990, 1997; Park et al. 1994b). In this case, there would be no gradient of $\mathrm{Fz}$ activation across the tissue, but instead an intracellular gradient of $\mathrm{Fz}$ activity (Fig. 2D). Because both models are able to explain the directional nonautonomy of $f z$ phenotypes in the wing and eye, it is not immediately possible to determine which is correct.

An interesting property of $\mathrm{Fz}$ is that during the final stages of cell polarization, it becomes asymmetrically localized within cells. In the wing, $\mathrm{Fz}$ localizes to the distal cell edge, from where the distally pointing hair subsequently emerges (Fig. 2E) (Strutt 2001). Similarly, in the eye, Fz localizes to the R3 side of the R3/R4 photoreceptor boundary (Strutt et al. 2002), apparently as part of the process of specifying R3/R4 cell fate, which is a critical step in polarizing the ommatidial cluster and
Gradients and the Specification of Planar Polarity

is known to be biased by higher $\mathrm{Fz}$ activity in the R3 cell than the R4 cell (Fig. 2F) (Zheng et al. 1995; Cooper and Bray 1999; Fanto and Mlodzik 1999; Tomlinson and Struhl 1999). A number of other proteins are required for $\mathrm{Fz}$ asymmetric localization and the establishment of planar polarity, and are themselves asymmetrically localized along with $\mathrm{Fz}$ in the junctional region of polarizing cells (Fig. 2E,F) (for review, see Klein and Mlodzik 2005; Zallen 2007), and are collectively referred to as the "core" planar polarity proteins.

At a minimum, the asymmetric localization of the core proteins provides an explanation for the essential cell-autonomous requirements for each of these proteins in planar polarity determination in the wing and eye. In their absence, there is no asymmetric subcellular cue provided by their localization, and both wing hairs and ommatidia in the eye are mispolarized. Additionally, it also provides a potential mechanism for local coordination of cell polarity, as the asymmetric complexes spanning the junctions between neighboring cells couples their polarity. As previously suggested by Adler, such cell-cell propagation of polarity could explain the nonautonomous phenotypes around $f z$ clones, and a number of groups have presented models based on this idea (Fig. 1G) (Tree et al. 2002; Amonlirdviman et al. 2005; Klein and Mlodzik 2005; Le Garrec et al. 2006).

The analysis of $f z$ function and planar polarity in Drosophila presented thus far illustrates significant similarities to the conclusions from grafting experiments in insects. In both contexts, planar polarity specification depends on polarized local interactions between cells. In addition, the polarity changes produced by either grafts or mosaic clones can be explained by reference to either changes in the slope of a gradient or by cell-cell propagation of polarity. The cell-cell propagation model is circumstantially supported by the observation of core protein asymmetric localization; however, whether it is correct depends on the relative contribution of cell-cell propagation of polarity via the core protein asymmetric complexes, and the influence of other upstream 
D. Strutt
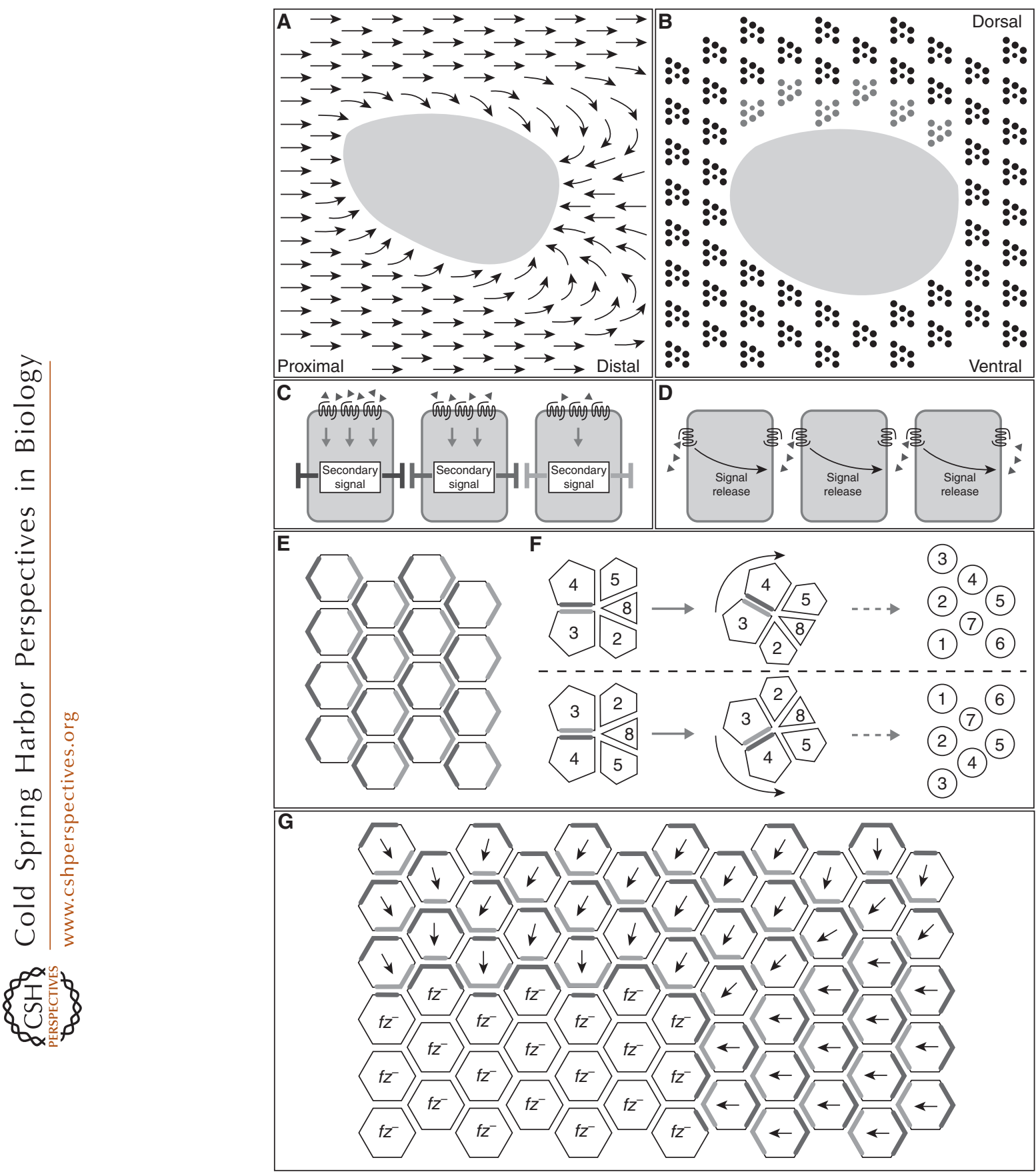

Figure 2. Frizzled and the determination of planar polarity in Drosophila. (A) Diagram showing the effects of loss of $f z$ activity from a clone of cells in the Drosophila wing. Normal hair polarity (arrows) is from proximal to distal; however, around a $f z$ clone (gray), hairs point towards the clone. (B) Groups of photoreceptors (ommatidia, black) show a distinct polarity on the dorsoventral (DV) axis of the eye. A clone of cells lacking $f z$ activity (gray region) in the dorsal half of the eye cause ommatidial dorsal to the clone (i.e., on the "polar" side relative to the dorsoventral midline) to show inverted DV polarity (gray). (Continued) 
polarity-specifying signals, such as gradients, to the final polarity pattern.

The following sections specifically consider what is known about the contribution of graded gene activities to the determination of planar polarity in the Drosophila cuticle.

\section{Gradients in the Eye}

In the Drosophila eye, current evidence suggests that the primary signal acting to specify planar polarity on the DV axis is the graded distribution of the secreted Wingless (Wg) ligand. The key observations were that overexpression of Wg in clones of cells in the eye causes extensive inversions of the DV polarity of ommatidia both within and outside the polar edge (i.e., the edge furthest from the equatorial midline), whereas clones of cells that are blocked for $\mathrm{Wg}$ signal transduction cause DV inversions on the equatorial edge of clones (Tomlinson et al. 1997; Wehrli and Tomlinson 1998). The nonautonomous nature of the defect, straddling the boundaries of clones of cells that are cell autonomously blocked in Wg signal transduction, most simply fits a model in which graded Wg signaling controls the production of a nonautonomously acting polarity signal provisionally named "Factor X" (after Struhl et al. 1997a), the slope of which specifies ommatidial polarity (Fig. 3A,B). As Wg itself is expressed at the poles of the eye, a possible assumption would be that Wg negatively regulates Factor $\mathrm{X}$, which is thus low at the poles and high at the equator. Higher Factor $\mathrm{X}$ activity would then lead, directly or indirectly, to higher Fz activity in the more equatorial of the R3/R4 photoreceptor pair, causing this cell to localize Fz to the R3/R4 boundary and take on R3 fate (Zheng et al. 1995; Strutt et al. 2002), thus specifying the appropriate DV polarity of the ommatidium.

Shortly after this discovery of the action of the Wg signaling pathway, the JAK/STAT signal transduction cascade was also shown to have a similar nonautonomous effect on ommatidial polarity in the eye (Zeidler et al. 1999a). The ligand for this pathway, Unpaired (Upd) is expressed at the equator of the eye, and clones of cells expressing Upd lead to nonautonomous inversions of ommatidial polarity on the equatorial edges of clones, whereas clones removing JAK receptor function result in polar inversions of ommatidial polarity

Figure 2. (Continued). (C) Model for Fz function in nonautonomously specifying planar polarity, through production of a gradient of a secondary signal. The Fz receptor is activated in a gradient across the axis of the wing by an extracellular ligand gradient (triangles). Fz activity then induces a gradient of a secondary signal which acts nonautonomously (e.g., via diffusion) to specify cell polarity. (D) Model for Fz function through passing a polarized signal from cell to cell. Each cell is proposed to transduce a polarity signal (triangles) via the Fz receptor and respond by polarizing itself and secreting the same signal at the opposite cell edge, which in turn polarizes the neighboring cell. $(E)$ Diagram showing the asymmetric localization of $\mathrm{Fz}$ and the core polarity proteins in the junctional regions of pupal wing cells. Fz and a number of other proteins localize in a junctional complex at the distal cell edge (light gray), whereas a reciprocal complex of different composition forms at the proximal cell edge (dark gray). (F) Asymmetric localization of $\mathrm{Fz}$ and the core polarity proteins in the R3/R4 photoreceptor pair and the determination of ommatidial polarity. Early in ommatidial assembly, the ommatidium consists of five photoreceptors (R3, R4, R5, R8, and R2) and is polarized only on the AP axis. Within the most anterior pair of photoreceptors (R3/R4), Fz becomes localized to the R3/R4 cell-cell boundary on the side closest to the equatorial midline of the eye (dotted line), causing the cell closest to the midline to take on R3 fate and the cell further away to take on R4 fate. As a result of this cell fate decision, ommatidia dorsal to the midline rotate clockwise and those ventral rotate anticlockwise, resulting in ommatidia with opposite DV polarities. $(G)$ Model to explain nonautonomous polarity changes around an $f z$ clone in the wing, based on coupling of cell polarities via junctional assembly of asymmetric core planar polarity complexes. Cells within the clone cannot form Fz-containing complexes, and so form the reciprocal proximal complex (dark gray) with cells surrounding the clone. These cells in turn assemble Fz-containing distal complexes (light gray) around the clone edges, and this abnormal polarity of asymmetric complex assembly is propagated to surround cells, such that they take on abnormal polarity. 
D. Strutt
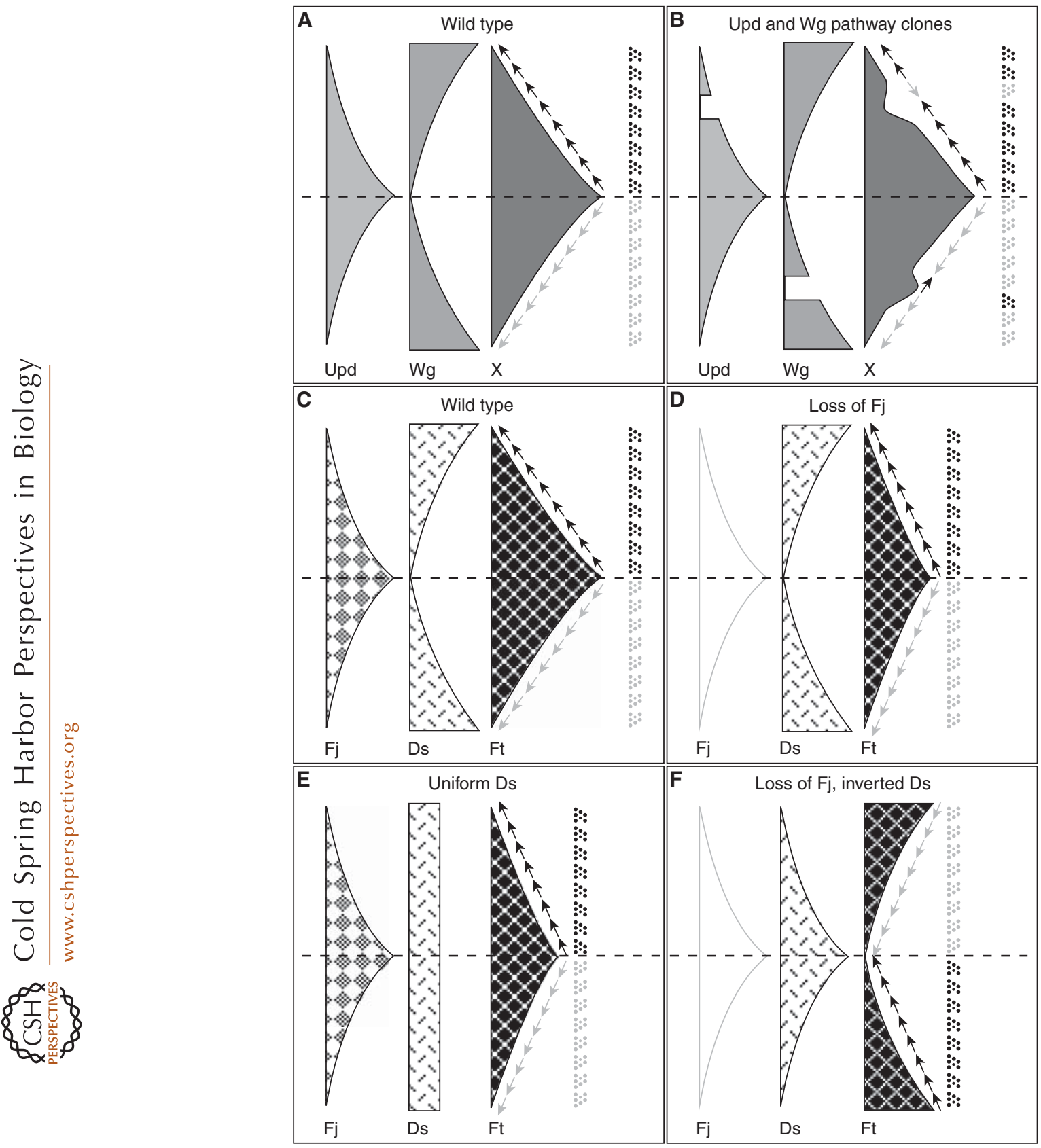

Figure 3. Gradients and the specification of ommatidial DV polarity in the Drosophila eye. (A) Model for the activities of the Unpaired (Upd) and Wg pathways in the eye, regulating a graded factor ("X") that specifies ommatidial polarity. The Upd ligand is expressed at the equator and forms a gradient of activation of the JAK/STAT signal transduction pathway (light gray), whereas Wg is expressed at the dorsal and ventral poles of the eye and similarly generates a gradient of pathway activation (mid gray). A nonautonomously acting factor X (dark gray) is positively regulated by Upd signaling and negatively regulated by $\mathrm{Wg}$ signaling. The slope of X specifies ommatidial DV polarity (arrows). (B) Model to explain the phenotypes of clones that block Upd or Wg signal transduction. (Continued) 
(Fig. 3A,B). A unified model was presented in which $\mathrm{Wg}$ at the poles represses production of Factor X, and Upd at the equator activates it, with the resulting graded distribution of Factor $\mathrm{X}$ again specifying ommatidial polarity by regulating $\mathrm{Fz}$ activity in the $\mathrm{R} 3 / \mathrm{R} 4$ photoreceptor pair.

Initial speculation centered around the possibility that Factor X would be another secreted signaling molecule. Furthermore, as members of the $\mathrm{Fz}$ protein family act as receptors for ligands of the Wnt family (Bhanot et al. 1996), it was suggested that Factor X might be a Wnt. However, extensive attempts to identify a Wnt that plays this role in either the eye, wing, or abdomen, have failed (e.g., Wehrli and Tomlinson 1998; Lawrence et al. 2002).

An alternative suggestion as to the identity of Factor X came from studies of the fourjointed ( $f j$ ) gene. Previous work characterized $f j$ as encoding a type II transmembrane protein that might also be cleaved and secreted to yield a diffusible ligand (Villano and Katz 1995; Brodsky and Steller 1996). Furthermore, $f j$ is expressed in a gradient in the eye, as predicted for Factor X. Loss of function or overexpression of $f j$ in clones in the eye was found to cause nonautonomous inversions of ommatidial polarity on either the polar or equatorial sides of clones, respectively (Zeidler et al. 1999b). In addition, the gradient of $f j$ expression is positively regulated by Upd and negatively regulated by $\mathrm{Wg}$. Based on this evidence, it was proposed that the $\mathrm{Fj}$ protein might be Factor X. However, there were two provisos to this conclusion. First, complete loss of graded expression of $f j$ did not cause
Gradients and the Specification of Planar Polarity

strong polarity defects, suggesting that $\mathrm{Fj}$ was only a component of Factor $\mathrm{X}$, and must act redundantly with another graded factor downstream of Wg and/or Upd. Second, it was not known if the secreted form of $\mathrm{Fj}$ was the active agent in planar polarity, and if it was not, then the nonautonomous activity would have to be mediated via some downstream factor.

Notably, in addition to its function in planar polarity, $\mathrm{Fj}$ is also required for $\mathrm{PD}$ limb patterning, a property it shares with the atypical cadherins encoded by the $f a t(f t)$ and dachsous $(d s)$ genes, with which it interacts genetically (Mohr 1923, 1929; Waddington 1943; Mahoney et al. 1991; Clark et al. 1995). $f t$ and $d s$ were also known to be required for planar polarity (Adler et al. 1998) and $d s$ is expressed in a gradient in the eye disc (Clark et al. 1995), high at the poles, as if positively regulated by $\mathrm{Wg}$. For these reasons, it seemed likely that $f j, f t$, and $d s$ might all act together in controlling planar polarity.

Confirmation of this hypothesis came from the work of Yang et al. (2002), which showed that $f j$ acted upstream of $f t$ and $d s$ in ommatidial polarity determination. This and other work showed that within clones of cells lacking $f t$ and $d s$, ommatidial DV polarity was randomized (Rawls et al. 2002; Strutt and Strutt 2002; Yang et al. 2002; Fanto et al. 2003), indicating an essential role for $f t$ and $d s$ activity in ommatidial polarity specification. Furthermore, $f t$ clones mimic $f j$ clones in showing nonautonomous polarity inversions on their polar edges, whereas $d s$ clones resemble $f j$ overexpression and show nonautonomy on their polar edge. This and other data suggested that the

Figure 3. (Continued). A clone blocking Upd transduction (upper part of panel) causes a trough in the gradient of $\mathrm{X}$, causing a change in the slope on the polar side of the clone and polar inversions of ommatidial polarity. A clone blocking Wg transduction (lower part of panel) causes a peak in the gradient of $\mathrm{X}$, and inversion of ommatidial polarity on the equatorial side of the clone. $(C)$ Model showing equatorial-to-polar gradient of Four-jointed (Fj) expression and polar-to-equatorial gradient of Dachsous (Ds) expression acting together to produce an equatorial-to-polar gradient of Fat (Ft) activity (Ft being uniformly expressed). Ommatidial polarity is specified by the slope of the gradient of Ft activity (arrows). (D) Loss of Fj does not cause significant ommatidial polarity defects, as the Ds expression gradient is sufficient to provide graded $\mathrm{Ft}$ activity. (E) Uniform expression of Ds, with graded $\mathrm{Fj}$ expression, is also sufficient to provide graded $\mathrm{Ft}$ activity. However, Ds expression cannot be dispensed with, as Fj acts by modulating the Ft/Ds interaction and in the absence of $\mathrm{Ds}, \mathrm{Fj}$ cannot modulate Ft activity. $(F)$ Loss of $\mathrm{Fj}$ and inversion of the Ds gradient causes inversion of ommatidial polarities. 
D. Strutt

equatorial-to-polar gradient of $\mathrm{Fj}$ expression, and the polar-to-equatorial gradient of Ds expression, led to an equatorial-to-polar gradient of Ft activity (Ft protein being uniformly distributed) (Fig. 3C).

Yang and colleagues (2002) presented a model in which higher Ft activity in the equatorial member of the R3/R4 photoreceptor pair caused an increase in $\mathrm{Fz}$ activity, and thus this cell takes on R3 fate and polarizes the ommatidium. According to this interpretation, Ft activity fits the criterion for being Factor X, as in its absence ommatidia receive no polarity cue and thus take on a random polarity, and the gradient of Ft activity across the ommatidium determines its ultimate polarity. However, this model cannot readily explain the nonautonomous phenotypes of $f t$ and $d s$ clones, and arguments have been made against a cell-autonomous action of Ft activity in the R3/R4 photoreceptor pair, with it instead being proposed that $\mathrm{Fj} / \mathrm{Ft} / \mathrm{Ds}$ are upstream of other unidentified nonautonomously-acting polarity signals (Rawls et al. 2002; Fanto et al. 2003). The direct linkage of Fj/Ft/Ds to activation of $\mathrm{Fz}$ is also contentious because it had been noted previously that $\mathrm{Fj}$ activity is oppositely correlated with $\mathrm{Fz}$ activity in the eye and the wing (Zeidler et al. 2000), arguing for a more indirect mechanism.

An important test of the importance of the $\mathrm{Fj}$ and Ds expression gradients for specifying ommatidial polarity is to show that directly altering the graded expression has the expected effects, and this is indeed the case. Inverting the $\mathrm{Fj}$ gradient so that it is high at the poles of the eye causes ommatidia at the poles to show inverted DV polarity (Simon 2004; Strutt et al. 2004), and similarly inverting the Ds expression gradient (and at the same time removing the competing Fj gradient) causes complete reversal of ommatidial polarity around the equator (Simon 2004). Furthermore, it was shown that the Ds and Fj expression gradients act as redundant cues for ommatidial polarity determination (Fig. 3D-F).

Overall, based on both the observed expression patterns and genetic analysis, there is an excellent case for believing that Wg expressed at the poles of the eye, and probably Upd expressed at the equator, act to specify ommatidial polarity by activating graded expression of $\mathrm{Fj}$ and $\mathrm{Ds}$ in the eye, which act together with Ft. However, how this graded expression/ activity of $\mathrm{Fj} / \mathrm{Ft} / \mathrm{Ds}$ acts as an instructional cue remains mysterious. The simplest model is that different levels of Ft activity exist between adjacent cells, and that a downstream mechanism reads this to provide each cell with a polarity cue. However, an alternative model is that the tissue level gradients of $\mathrm{Fj}$ and $\mathrm{Ds}$ activity are somehow converted directly into intracellularly graded Ft activity, and thus it is Ft activity within a cell rather than between cells that is the essential polarity cue (see Fig. 5C).

It is tempting to suppose, as presented by Yang et al. (2002), that $\mathrm{Fj} / \mathrm{Ft} / \mathrm{Ds}$ act strictly upstream of Fz and the other core planar polarity proteins, and provide their only polarity input. It is certainly likely that the $\mathrm{Fj} / \mathrm{Ft} / \mathrm{Ds}$ cues do ultimately act to specify ommatidial polarity through polarized localization of the core proteins in the R3/R4 photoreceptor pair. However, in terms of locally coordinating cell polarity, genetic evidence suggests that $\mathrm{Fj} / \mathrm{Ft} / \mathrm{Ds}$ may act in parallel to $\mathrm{Fz}$ in the eye (Strutt and Strutt 2002), as also appears to be the case in the wing (Adler et al. 1998), and has been shown in the abdomen (Casal et al. 2006) (see later). Furthermore, in the absence of detailed knowledge of the mechanism underlying $\mathrm{Fz}$ asymmetric localization in the R3/R4 photoreceptor pair, it is perfectly conceivable that there may be other sources of polarity information other than $\mathrm{Fj} / \mathrm{Ft} / \mathrm{Ds}$.

It is also interesting to note that, although Wg and Upd act via graded $\mathrm{Fj} / \mathrm{Ft} / \mathrm{Ds}$ expression to specify ommatidial polarity, they also act to specify the equator at the midline of the eye, which acts as a boundary around which polarity is organized. Early activity of Wg and Upd in the developing eye serves to restrict expression of transcription factors of the Iroquois Complex to the dorsal half of the eye (McNeill et al. 1997; Heberlein et al. 1998; Cavodeassi et al. 1999; Zeidler et al. 1999a), which represses expression of the glycosylase Fringe, leading 
to activation of the Notch signaling pathway in a band of cells along the midline (Cho and Choi 1998; Domínguez and de Celis 1998; Papayannopoulos et al. 1998). This stripe of Notch acts as an organizing center for ommatidial polarity, causing polarity to be inverted on either side, thus creating the equator. How Notch alters ommatidial polarity in this context, and how it interacts with other polarity cues, is not understood; although, as Notch activates $\mathrm{Fj}$ (Papayannopoulos et al. 1998; Zeidler et al. 1999b), it may be that its effects are mediated via $\mathrm{Ft} / \mathrm{Ds}$.

Given that the equator is defined with great precision, with ommatidia of different polarities never mixing, it is questionable whether it could simply be defined by the peak of a gradient of a nonautonomously acting factor such as the elusive Factor X (or indeed Fj), because the nonautonomy of their action would tend to smooth the peak of the gradient. Instead, it has been suggested that the restricted expression of the Iroquois Complex transcription factors may also specify a difference in cell affinity between dorsal and ventral cells, such that the equator acts like a segmental boundary (Yang et al. 1999). In this case, at least locally, polarity might propagate from the equator by a cell-cell relay mechanism, such as that potentially provided by $\mathrm{Fz}$ and the core polarity proteins, with gradients only serving to specify polarity over longer distances.

Thus, in the Drosophila eye, as previously suggested by grafting experiments in other insects, there is good evidence for gradients being involved in specifying cell polarity over long distances, but also the possibility of cell-cell interactions at boundaries providing polarity cues.

\section{The Missing Gradients in the Wing}

In the wing, as in the eye, $\mathrm{Fj} / \mathrm{Ft} / \mathrm{Ds}$ play important roles in specifying planar polarity, which is again ultimately determined by the asymmetric localization of $\mathrm{Fz}$ and the core planar polarity proteins, along the $\mathrm{PD}$ axis of each cell (in this case). Nevertheless, despite these similarities, how PD polarity information is specified is
Gradients and the Specification of Planar Polarity

poorly understood. In particular, no direct role for a secreted signal that might form a gradient has been established. Wg and Upd, which play this role in the eye, apparently do not specify planar polarity in the wing by providing graded cues, because clones of cells in the wing blade that are blocked for transduction of these pathways do not result in polarity defects (Axelrod et al. 1998; Zeidler et al. 2000). Similarly, there is no evidence for other morphogens involved in wing patterning, such as Hedgehog ( $\mathrm{Hh})$ and Decapentaplegic (Dpp), directly specifying polarity. Nevertheless, the Wg pathway does play a major role in specifying the PD axis of the wing, and thus seems likely to ultimately lie upstream of PD planar polarity cues: for instance, by specifying the position of boundaries such as the wing margin and wing hinge.

The only known molecule with PD-graded expression throughout a significant proportion of the wing, that also plays a role in planar polarity specification, is $\mathrm{Fj}$ (Zeidler et al. 2000), which is high at the distal tip and fades towards proximal regions. Ds is strongly expressed in the hinge region of the wing, but shows at best weak evidence of a PD gradient in only the most proximal regions of the wing proper (Strutt and Strutt 2002; Ma et al. 2003; Matakatsu and Blair 2004). Nevertheless, similar to what was proposed in the eye, it was put forward that gradients of Ds/Ft activity were the primary polarity signals in the wing that act to polarize $\mathrm{Fz}$ asymmetric localization (Ma et al. 2003). Evidence was quickly forthcoming that this was unlikely to be true. Two groups showed that in the absence of the Fj gradient, uniform Ds was sufficient for normal planar polarity throughout all but the most proximal regions of the wing (Matakatsu and Blair 2004; Simon 2004), as was uniform expression of a form of Ft lacking the extracellular domain, and thus presumably unable to interact with any extracellular graded signal (Matakatsu and Blair 2006).

What then are the signals that ensure that $\mathrm{Fz}$ becomes localized distally in cells? Ft and Ds are necessary for normal patterning, because in their absence, the core polarity proteins localize 
D. Strutt

asymmetrically in swirling patterns, instead of just at PD cell boundaries (Strutt and Strutt 2002; Ma et al. 2003), and so the gradient of $\mathrm{Fj}$ expression seen in the wing could be acting to reinforce the normal polarity pattern. But, overall, it seems likely that some other unidentified signals are essentially required. Intriguingly, there is evidence that $\mathrm{Fz}$ distal localization is in part dependent on PD polarization of the microtubule cytoskeleton. The protein phosphatase $2 \mathrm{~A} \mathrm{~B}^{\prime}$ subunit, encoded by the Widerborst gene, has been shown to localize to the distal cell ends on microtubules, and in its absence, $\mathrm{Fz}$ asymmetry is disrupted (Hannus et al. 2002). Furthermore, Fz has been shown to be transported to the distal cell end on a polarized microtubule array (Shimada et al. 2006). The overall contribution of microtubule polarity to Fz asymmetry is not yet established. However, it could be the case that Ft/Ds are required for microtubule polarization, but in the absence of their graded activity, Fz becomes polarized by a different mechanism. Alternatively, the polarization of microtubules could act in parallel to Ft/Ds, and explain why $\mathrm{Ft} / \mathrm{Ds}$ gradients are not essentially required in the wing.

It has been suggested that the failure to identify a single long-range organizing system in the wing may indicate that planar polarity is normally specified by a patchwork of mechanisms acting in different regions (Matakatsu and Blair 2004). In this case, a mixture of both gradients and borders, combined with local cellcell propagation, could specify the overall polarity pattern. If some of these mechanisms acted redundantly with each other, it might prove particularly difficult to elucidate the final mechanism.

\section{The Abdomen - The Antarctica of Planar Polarity Research}

Like Antarctica, although exploration of planar polarity patterning in the abdomen was neglected for many years, it is now seeing a resurgence of interest that has led to important discoveries. As described, the wing has not proved fruitful for understanding long-range patterning mechanisms, and the eye is a relatively complex and specialized structure that might not represent a good model for elucidating general principles.

The abdomen consists of a chain of segments, each of which is divided into anterior (A) and posterior (P) compartments, with each compartment further regionalized into cells of different fate (Fig. 4). Planar polarity is evident in the posterior orientation of bristles and hairs over much of the dorsal surface and of hairs over the ventral surface. Thus, over the abdomen as a whole, there is a uniform $\mathrm{A}$ to $P$ planar polarity, superimposed on a repeating pattern of boundaries between different cell fates. As will be described, these boundaries, and in particular those between adjacent compartments, act as organizing centers for planar polarity. A key question is to what extent they acts as sources of long-range graded cues, and to what extent they only locally organize polarity that is then propagated from cell to cell by relay mechanisms.

The key signal organizing cell fate in the AP axis of the abdomen is the secreted factor Hh (Kopp et al. 1997; Struhl et al. 1997b). Hh is expressed throughout the $\mathrm{P}$ compartment through the action of the selector gene engrailed, and is believed to form a U-shaped gradient in the A compartment (Fig. 4). At the posterior of the A compartment, $\mathrm{Hh}$ induces the expression of $\mathrm{Wg}$, which is then thought to form additional gradients through the $\mathrm{A}$ and $\mathrm{P}$ compartments (Lawrence et al. 2002). Acting at least in part through the transcription factor Omb (Kopp and Duncan 1997; Lawrence et al. 2002), $\mathrm{Hh}$ and $\mathrm{Wg}$, according to their levels, then autonomously specify cell fate in the A and P compartments, respectively (Struhl et al. 1997a; Lawrence et al. 2002).

The vectors of the Hh and Wg gradients also specify planar polarity, although this seems to be indirect, because the effects are nonautonomous and there is no simple relationship between the slope of $\mathrm{Hh}$ concentration and cell polarity (Struhl et al. 1997a; Lawrence et al. 2002): In the anterior of the A compartment, hairs point down the gradient of $\mathrm{Hh}$, 


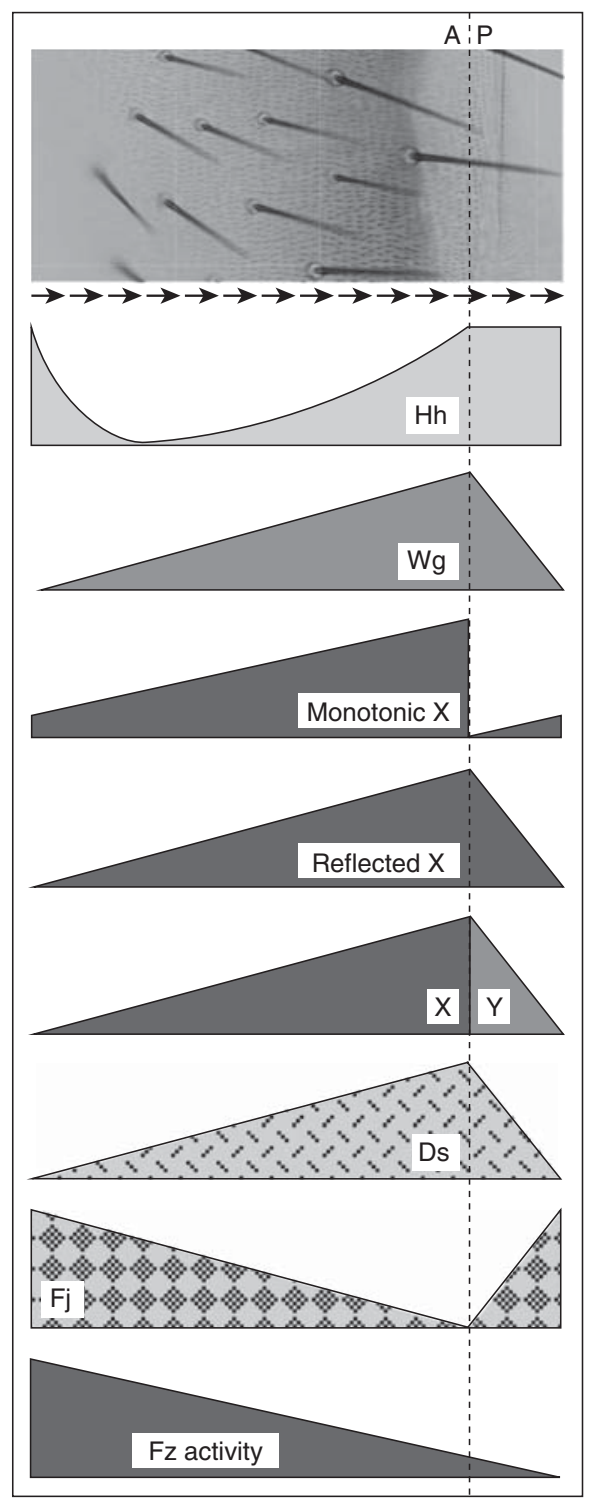

Figure 4. Gradients in the Drosophila abdomen. The abdomen is composed of a series of repeating segments, from anterior to posterior, each divided into anterior $(\mathrm{A})$ and posterior $(\mathrm{P})$ compartments at the $\mathrm{A} / \mathrm{P}$ compartment boundary (dotted line). Adjacent segments are separated by the segmental boundary that also corresponds to the $\mathrm{P} / \mathrm{A}$ compartment boundary. The photograph (top) shows a single segment, anterior to the left, posterior to the right, with hairs and bristles pointing posteriorly. Diagrams show putative gradients of factors involved in patterning fate and polarity in the abdomen, with the anterior compartment on the left and the posterior compartment on the right.
Gradients and the Specification of Planar Polarity

whereas in the posterior part, they point up the gradient. The term "Factor X" was first coined to refer to a nonautonomously polarizing activity downstream of $\mathrm{Hh}$, and in the absence of molecular evidence as to its identity, it was proposed either that it might form a monotonic gradient across pairs of $\mathrm{P}$ and A compartments (the "parasegmental" unit), a reflected gradient around the $\mathrm{A} / \mathrm{P}$ compartment boundary, or that $\mathrm{X}$ would form a gradient across the $\mathrm{A}$ compartment from the $\mathrm{A} / \mathrm{P}$ boundary and another factor "Y" would form an analogous polarizing gradient in the $\mathrm{P}$ compartment (Fig. 4) (Lawrence et al. 1999, 2002). In each of these cases, the $\mathrm{A} / \mathrm{P}$ boundary plays a special role as an organizing center for polarity in the segment.

As in the eye, $f j, d s$, and $f t$ play key roles in organizing planar polarity (Casal et al. 2002). $f j$ and $d s$ have opposing expression gradients in the $\mathrm{A}$ and $\mathrm{P}$ compartments, reflected about the A/P compartment boundary (Fig. 4), and the nonautonomous effects of clones indicate that the vectors of these gradients, and of $f t$ activity, specify planar polarity. It was thus proposed that in the abdomen, $\mathrm{Fj} / \mathrm{Ft} / \mathrm{Ds}$ at least in part constituted Factor X or contributed to its production. It was noted that as polarity points down the $f j$ gradient in the A compartment, and up it in the $\mathrm{P}$ compartment, there was no direct relationship between $\mathrm{Fj} / \mathrm{Ds} / \mathrm{Ft}$ activity and hair polarity (Casal et al. 2002), similar to what had been noted previously for the relationship between $f j$ activity and $f z$ activity in the eye and wing (Zeidler et al. 2000).

$f z$ and the core polarity proteins are also required for planar polarity specification in the abdomen (Lawrence et al. 2004), with $f z$ clones showing nonautonomous inversions of hair polarity on the posterior edges of clones in both $\mathrm{A}$ and $\mathrm{P}$ compartments. Thus, $f z$ activity has a constant relationship to hair polarity, suggesting that as in the eye and wing, $f z$ function may be closely linked to the final polarity decision. To explain the nonautonomous phenotypes, a model was presented in which $\mathrm{Fz}$ activity is graded from $\mathrm{A}$ to $\mathrm{P}$, and cells compare their levels of $\mathrm{Fz}$ activity and adjust their levels to smooth the gradient (see next section). 
D. Strutt

The Fz activity gradient was proposed to be established in response to Factor X, and thus Factor $\mathrm{X}$ would have to decrease across each compartment from A to P. Interestingly, $\mathrm{Fj} /$ Ft/Ds do not fit this criterion for Factor X, having gradient activity that is reflected about the $\mathrm{A} / \mathrm{P}$ compartment boundary. It was suggested that the gradient of $\mathrm{X}$ might be rectified in one of the compartments to overcome this difficulty, but, in fact, the same group soon after made new discoveries regarding the relationship of $\mathrm{Fj} / \mathrm{Ft} / \mathrm{Ds}$ and $\mathrm{Fz}$, which rendered this explanation unnecessary.

They had previously noted that loss of either $f z$ activity or $f j / f t / d s$ activity did not lead to complete randomization of polarity in the abdomen (Casal et al. 2002), which would be hard to explain if there was a simple linear system in which $\mathrm{Fj} / \mathrm{Ft} / \mathrm{Ds}$ constituted Factor $\mathrm{X}$ and provided the only polarity input to $\mathrm{Fz}$ that in turn was the only factor responsible for polarizing cells. In fact, animals doubly mutant for both pathways showed a stronger phenotype (Casal et al. 2006). Furthermore, clones with altered activity of both pathways showed nonautonomy on both the $\mathrm{A}$ and $\mathrm{P}$ sides of clones, similar to what had been previously reported in the eye (Strutt and Strutt 2002). These results suggest that $\mathrm{fj} / \mathrm{ft} / \mathrm{ds}$ and $f z$ activities actually act in parallel in the abdomen. Further investigation showed that it was unlikely that the $f z$ system received a polarity input from $f j / f t / d s$, and vice versa. Indeed, elegant experiments in which the $\mathrm{Hh}$ pathway was activated in different mutant backgrounds showed that $\mathrm{Fz}$ and $\mathrm{Fj} / \mathrm{Ft} / \mathrm{Ds}$ were most likely independently receiving polarizing information from the Hh signal.

$\mathrm{As} \mathrm{Fz}$ and the core polarity proteins were no longer tenable candidates for providing nonautonomous polarity coordination downstream of $\mathrm{Fj} / \mathrm{Ft} / \mathrm{Ds}$, a model was presented in which interactions between Ft and Ds themselves acted to interpret the graded information provided by the expression gradients of Fj and Ds, both providing individual cells with a polarity cue and locally propagating polarity information between cells (Casal et al. 2006) (see next section).
In summary, there are good reasons for believing that gradients act to specify planar polarity in the abdomen, and gradient-based models have been presented that can explain the observed phenotypes. However, as in the eye and wing, the molecular details of mechanisms at work remain to be fully elucidated, and it is still not possible to say to what extent gradients are responsible for patterning the whole tissue, or whether they act together with boundaries and local cell-cell relays. In the abdomen, this is a particular issue, because the morphogenetic gradients set up numerous boundaries between cell fates, any one of which could locally align cell polarities. Indeed, it has been noted that if gradients alter at compartment boundaries, then compartment boundaries must have the property of acting as barriers for transmission of the gradient, and that it is difficult to ensure peak gradient activity in the first rows of cells of the compartment (Struhl et al. 1997a,b; Lawrence et al. 1999, 2002).

\section{MODELS OF GRADIENT ACTION}

Thus far, the experimental evidence discussed shows that molecular gradients exist in the eye, wing, and abdomen, and that these are responsible for organizing planar polarity. It has also been noted that despite the elegance and consequent appeal of gradient models, too little is known about the underlying molecular mechanisms to know at exactly what levels gradients act. Are individual cells universally involved in the process of reading extrinsic gradients, or in some cases are gradients only acting to specify boundaries of cell fate that serve as organizing centers for local cell polarity?

To attempt to answer these questions, a number of groups have recently put forward models based on the experimental observations that probe the issue of how gradients might act to polarize cells. A common feature of all these models is that a gradient is ultimately responsible for biasing polarity throughout the axis of the tissue, because it is difficult to imagine how a polarizing boundary coupled to a cellcell relay could accurately polarize over long 
distances. Nevertheless, the models differ in the mechanism by which the gradient is proposed to act.

As already described, before the observation of core planar polarity protein subcellular asymmetry, two distinct classes of models for $\mathrm{Fz}$ action in propagating planar polarity had been put forward by the Adler laboratory (Fig. 2C,D) (e.g., Adler et al. 1997), in which there was either a tissue-level gradient of $\mathrm{Fz}$ activity that proportionately activated a locally acting nonautonomous secondary signal, or an intracellular gradient of $\mathrm{Fz}$ activity that was propagated by a cell-cell relay.

The discovery of $\mathrm{Fz}$ asymmetry gave a boost to cell-cell relay models as a means of locally coordinating polarity, and also led to the abandonment of the idea that there might be a diffusible ligand downstream of $\mathrm{Fz}$, it instead being generally proposed that polarity signals downstream of $\mathrm{Fz}$ passed between cells via the core polarity protein complexes at the cell junctions. Nevertheless, there is still the issue of how Fz acquires its initial asymmetry within cells.

Three models have been presented that propose that some aspect of $\mathrm{Fz}$ activity might be graded across the tissue, and that this drives the acquisition of Fz asymmetry (Amonlirdviman et al. 2005; Klein and Mlodzik 2005; Le Garrec et al. 2006). By modeling the inferred interactions between the core polarity proteins, all three groups very satisfyingly found that the presumed activity gradient of $\mathrm{Fz}$, which is high proximally and low distally in the wing, would be predicted to result in an $\mathrm{Fz}$ distribution that, at the cellular level, is low proximally and high distally, as is in fact observed (Fig. 5A). Hence, each of these models is able to explain how a long-range gradient of Factor X, which activates $\mathrm{Fz}$ proportionately in each cell, can generate subcellular asymmetry. The main difference between these models is that, as presented, the Le Garrec et al. and Klein and Mlodzik models assumed that only "activated" $\mathrm{Fz}$ can incorporate into asymmetric junctional complexes, and thus a gradient of levels of asymmetric $\mathrm{Fz}$ might be expected to be observed across the axis of this tissue; whereas,
Gradients and the Specification of Planar Polarity

in Amonlirdviman et al., the difference in $\mathrm{Fz}$ activity is subsequently amplified such that all cells would be expected to show equal levels of asymmetric $\mathrm{Fz}$ localization. So far, there has been no report of differences in levels of asymmetric $\mathrm{Fz}$ across the axis of a tissue, but this might be difficult to detect if the effect was subtle.

Two alternative models, which have already been mentioned, for coordination of polarity by $\mathrm{Fz}$ and the core polarity proteins (Lawrence et al. 2004) and by $\mathrm{Fj} / \mathrm{Ft} / \mathrm{Ds}$ (Casal et al. 2006), do not rely on the gradual acquisition of asymmetric subcellular protein localization. In the first, Factor $\mathrm{X}$ leads to a gradient of $\mathrm{Fz}$ activity that is then signaled to neighboring cells via junctional complexes of the core polarity proteins, leading cells to adopt the average value of $\mathrm{Fz}$ activity presented by their neighbors until equilibrium is reached, after which $\mathrm{Fz}$ asymmetry is thought to be a downstream consequence (Fig. 5B). In this case, how the final differences in $\mathrm{Fz}$ activity between neighboring cells leads to Fz subcellular asymmetry (or indeed, some other well-defined cellular asymmetry that could act as a cue for polarized hair formation) is not understood. In the second model, heterophilic interactions between $\mathrm{Ft}$ and Ds in neighboring cells are biased by the tissue-level expression gradient of Ds, and the activity of Fj that acts on Ft to increase its affinity for Ds. Within each cell, the difference between the number of Ds-Ft heterodimers on each edge then acts as a polarity cue (Fig. 5C,D). However, it remains to be elucidated how an apparently subtle difference in the Ds-Ft heteodimer ratio is amplified to provide a strong polarity cue.

\section{CONCLUDING REMARKS}

Although there is strong evidence for gradients determining cell polarity, their actual mechanisms of action remain unclear. Determining which of the models presented is closest to the truth will necessitate understanding what is meant by concepts such as "Fz activity" at the molecular level. Similarly, we are only just beginning to understand what activates or biases 
D. Strutt

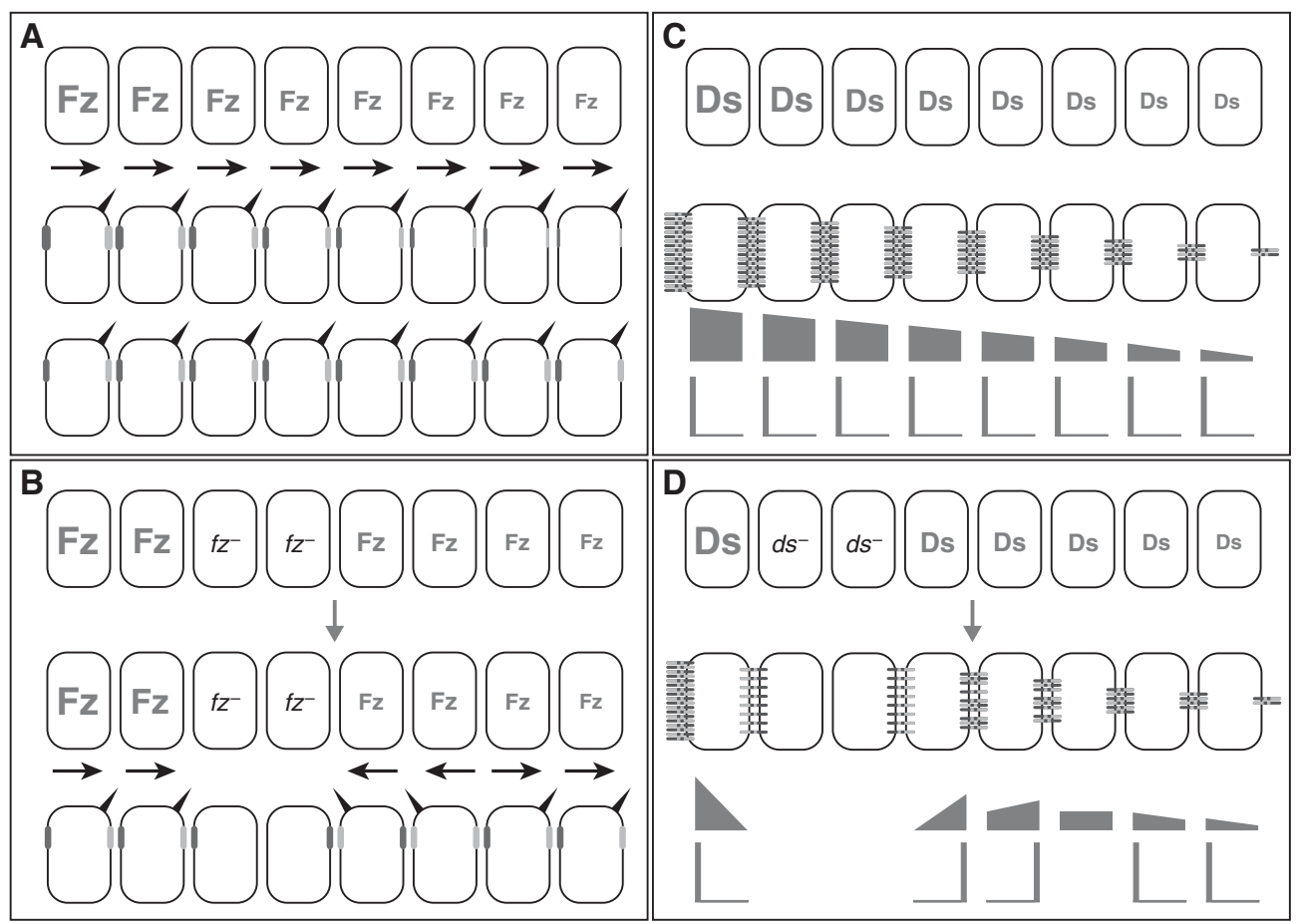

Figure 5. Models of gradient function and the polarization of individual cells. (A) Models for graded Fz activity being converted into Fz subcellular asymmetry via formation of asymmetric junctional complexes. An extrinsic gradient is assumed to produce a gradient of activated Fz across the tissue. For any particular cell, the next more proximal cell (left) has a higher concentration of activated Fz than the next more distal cell (right); hence, "proximal" junctional complex components (dark gray) in this cell prefer to form asymmetric complexes with "distal" Fz-containing complexes (light gray) in the more proximal cell. Consequently, each cell becomes polarized with proximal and distal complexes at opposite ends. If only "activated" Fz can participate in complex formation, then a gradient of amounts of protein in proximal and distal complexes would be expected (middle row of cells in diagram), but this has not been experimentally observed. If total cellular Fz can incorporate into complexes, once asymmetry has been established, then all cells will show the same concentration of complexes at junctions (bottom row of cells in diagram), which more closely fits the experimental observations. (B) Model in which cells compare levels of $\mathrm{Fz}$ activity, before establishment of $\mathrm{Fz}$ asymmetric localization, showing the effects of a clone of $f z$ mutant cells. An Fz activity gradient is established in the tissue, after which cells compare their levels with their neighbors and take on an average value. As $f z$ mutant cells have no Fz activity, this leads neighboring cells to take on a lower than normal level of Fz activity, causing an inversion of the gradient of Fz activity distally (to the right) of the clone. The different levels of $\mathrm{Fz}$ activity between neighboring cells then drive asymmetric subcellular localization of $\mathrm{Fz}$ via an unknown mechanism, possibly similar to that in panel $(A) .(C)$ Model for how Ds and Fj gradients might polarize cells. A gradient of Ds expression leads to a gradient of formation of Ds-Ft heterodimers between the edges of each cell. An opposing gradient of $\mathrm{Fj}$ expression (not shown) promotes this process by modulating the strength of Ds-Ft binding. By measuring the ratio of heterodimers between each cell edge, each cell can obtain a polarity cue. This cue would be expected to be an initially subtle gradient of heterodimer formation (third row in diagram), but might ultimately be amplified to provide a strong polarity cue (bottom row in diagram). (D) Application of the Ds-Ft heterodimer model to explain the nonautonomy seen around $d s$ clones. Cells lacking $d s$ can only form Ft-Ds heterodimers and not Ds-Ft heterodimers with their neighbors, which affects the availability of Ds in the neighboring cells for forming heterodimers with other neighbors. If cells determine their polarity by measuring the ratio of Ft-Ds to Ds-Ft heterodimers on their cell edges, then this would cause an inversion of cell polarity on the right side of the clone. 
this activity. In addition, the discovery that $\mathrm{Fj} / \mathrm{Ft} / \mathrm{Ds}$ can polarize cells independently of $\mathrm{Fz}$ and the core planar polarity proteins provides another set of molecular mysteries to be unraveled. More than half a century after it was first investigated, how gradients determine planar polarity remains an unsolved problem.

\section{REFERENCES}

Adler PN, Vinson C, Park WJ, Conover S, Klein L. 1990. Molecular structure of frizzled, a Drosophila tissue polarity gene. Genetics 126: $401-416$.

Adler PN, Krasnow RE, Liu J. 1997. Tissue polarity points from cells that have higher Frizzled levels towards cells that have lower Frizzled levels. Curr Biol 7: 940-949.

Adler P, Charlton J, Liu J. 1998. Mutations in the cadherin superfamily member gene dachsous cause a tissue polarity phenotype by altering frizzled signaling. Development 125: 959-968.

Amonlirdviman K, Khare NA, Tree DRP, Chen W-S, Axelrod JD, Tomlin CJ. 2005. Mathematical modeling of planar cell polarity to understand domineering non-autonomy. Science 307: 423-426.

Axelrod JD, Miller JR, Shulman JM, Moon RT, Perrimon N. 1998. Differential recruitment of Dishevelled provides signaling specificity in the planar cell polarity and Wingless signaling pathways. Genes Dev. 12: 2610-2622.

Bhanot P, Brink M, Samos CH, Hsieh J-C, Wang Y, Macke JP, Andrew D, Nathans J, Nusse R. 1996. A new member of the frizzled family from Drosophila functions as a Wingless receptor. Nature 382: 225-230.

Brodsky MH, Steller H. 1996. Positional information along the dorsal-ventral axis of the Drosophila eye: Graded expression of the four-jointed gene. Dev Biol 173: $428-446$.

Casal J, Struhl G, Lawrence P. 2002. Developmental compartments and planar polarity in Drosophila. Curr Biol 12: 1189.

Casal J, Lawrence PA, Struhl G. 2006. Two separate molecular systems, Dachsous/Fat and Starry night/Frizzled, act independently to confer planar cell polarity. Development 133: $4561-4572$.

Cavodeassi F, del Corral RD, Campuzano S, Domíngues M. 1999. Compartments and organising boundaries in the Drosophila eye: The role of the homeodomain Iroquois proteins. Development 126: 4933-4942.

Cho K-O, Choi K-W. 1998. Fringe is essential for mirror symmetry and morphogenesis in the Drosophila eye. Nature 396: 272-276.

Clark HF, Brentrup D, Schneitz K, Bieber A, Goodman C, Noll M. 1995. Dachsous encodes a member of the cadherin superfamily that controls imaginal disc morphogenesis in Drosophila. Genes Dev 9: 1530-1542.

Cooper MY, Bray SJ. 1999. Frizzled regulation of Notch signalling polarizes cell fate in the Drosophila eye. Nature 397: 526-530.
Domínguez M, de Celis JF. 1998. A dorsal/ventral boundary established by Notch controls growth and polarity in the Drosophila eye. Nature 396: 276-278.

Fanto M, Mlodzik M. 1999. Asymmetric Notch activation specifies photoreceptors R3 and R4 and planar polarity in the Drosophila eye. Nature 397: 523-526.

Fanto M, Clayton L, Meredith J, Hardiman K, Charroux B, Kerridge S, McNeill H. 2003. The tumor-suppressor and cell adhesion molecule Fat controls planar polarity via physical interactions with Atrophin, a transcriptional co-repressor. Development 130: 763-774.

Gubb D, García-Bellido A. 1982. A genetic analysis of the determination of cuticular polarity during development in Drosophila melanogaster. J Embryol Exp Morphol 68: 37-57.

Hannus M, Feiguin F, Heisenberg CP, Eaton S. 2002. Planar cell polarization requires Widerborst, a B' regulatory subunit of protein phosphatase 2A. Development 129: 3493-3503.

Heberlein U, Borod E, Chanut F. 1998. Dorsoventral patterning in the Drosophila retina by wingless. Development 125: 567-577.

Klein TJ, Mlodzik M. 2005. Planar cell polarization: An emerging model points in the right direction. Annu Rev Cell Dev Biol 21: 155-176.

Kopp A, Duncan I. 1997. Control of cell fate and polarity in the adult abdominal segments of Drosophila by optomotor-blind. Development 124: 3715-3726.

Kopp A, Muskavitch MA, Duncan I. 1997. The roles of hedgehog and engrailed in patterning adult abdominal segments of Drosophila. Development 124: 3703-3714.

Krasnow RE, Adler PN. 1994. A single frizzled protein has a dual function in tissue polarity. Development 120: 1883-1893.

Lawrence PA. 1966. Gradients in the insect segment: The orientation of hairs in the milkweed bug Oncopeltus fasciatus. J Exp Biol 44: 607-620.

Lawrence PA, Crick FHC, Munro M. 1972. A gradient of positional information in an insect, Rhodnius. J Cell Sci 11: 815-853.

Lawrence PA, Casal J, Struhl G. 1999. hedgehog and engrailed: Pattern formation and polarity in the Drosophila abdomen. Development 126: 2431-2439.

Lawrence PA, Casal J, Struhl G. 2002. Towards a model of the organisation of planar polarity and pattern in the Drosophila abdomen. Development 129: 2749-2760.

Lawrence PA, Casal J, Struhl G. 2004. Cell interactions and planar polarity in the abdominal epidermis of Drosophila. Development 131: 4651-4664.

Le Garrec JF, Lopez P, Kerszberg M. 2006. Establishment and maintenance of planar epithelial cell polarity by asymmetric cadherin bridges: A computer model. Dev Dyn 235: $235-246$.

Locke M. 1959. The cuticular pattern in an insect, Rhodnius Prolixus. J Exp Biol 36: 459-477.

Ma D, Yang CH, McNeill H, Simon MA, Axelrod JD. 2003. Fidelity in planar cell polarity signalling. Nature 421: 543-547.

Mahoney PA, Weber U, Onofrechuk P, Biessmann H, Bryant PJ, Goodman CS. 1991. The fat tumor suppressor gene in 
D. Strutt

Drosophila encodes a novel member of the cadherin gene superfamily. Cell 67: 853-868.

Marcus W. 1962. Untersuchungen über die Polarität der Rumpfhaut von Schmetterlingen. Roux's Arch Dev Biol 154: $56-102$.

Matakatsu H, Blair SS. 2004. Interactions between Fat and Dachsous and the regulation of planar cell polarity in the Drosophila wing. Development 131: 3785-3794.

Matakatsu H, Blair SS. 2006. Separating the adhesive and signaling functions of the Fat and Dachsous protocadherins. Development 133: 2315-2324.

McNeill H, Yang CH, Brodsky M, Ungos J, Simon MA. 1997. mirror encodes a novel PBX-class homeoprotein that functions in the definition of the dorsal-ventral border in the Drosophila eye. Genes Dev 11: 1073-1082.

Mohr O. 1923. Modifications of the sex ratio through a sexlinked semi-lethal in Drosophila melanogaster (besides notes on an autosomal section deficiency). In Studia Mendeliana: Ad centesimum diem natalem Gregori Mendelii a grata patria celebrandum, pp. 266-287. Apud Typos, Brünn, Czechoslovakia.

Mohr O. 1929. Exaggeration and inhibition phenomena encountered in the analysis of an autosomal dominant. Z Indukt Abstammungs-Vererbungsl 50: 113-200.

Nardi JB, Kafatos FC. 1976a. Polarity and gradients in lepidopteran wing epidermis. I. Changes in graft polarity, form and cell density accompanying transpositions and reorientations. J Embryol Exp Morphol 36: 469-487.

Nardi JB, Kafatos FC. 1976b. Polarity and gradients in lepidopteran wing epidermis. II. The differential adhesiveness model: Gradient of a non-diffusible cell surface parameter. J Embryol Exp Morphol 36: 489-512.

Nübler-Jung K. 1977. Pattern stability in insect segment: I. Pattern reconstitution by intercalary regeneration and cell sorting in Dysdercus intermedius Dist. In Roux's Arch Dev Biol 183: 17-40.

Nübler-Jung K. 1987a. Insect epidermis: Disturbance of supracellular tissue polarity does not prevent the expression of cell polarity. Roux's Arch Dev Biol 196: 286-289.

Nübler-Jung K. 1987b. Tissue polarity in an insect segment denticle patterns resemble spontaneously forming fibroblast patterns. Development 100: 171-177.

Nübler-Jung K, Grau V. 1987. Pattern control in insect segments: Superimposed features of the pattern may be subject to different control mechanisms. Roux's Arch Dev Biol 196: 290-294.

Nübler-Jung K, Mardini B. 1990. Insect epidermis: Polarity patterns after grafting result from divergent cell adhesions between host and graft tissue. Development 110: 1071-1079.

Papayannopoulos V, Tomlinson A, Panin VM, Rauskolb C, Irvine KD. 1998. Dorsal-ventral signaling in the Drosophila eye. Science 281: 2031-2034.

Park WJ, Liu J, Adler PN. 1994a. Frizzled gene expression and development of tissue polarity in the Drosophila wing. Dev Genet 15: 383-389.

Park WJ, Liu J, Adler PN. 1994b. The frizzled gene of Drosophila encodes a membrane protein with an odd number of transmembrane domains. Mech Dev 45: $127-137$.

Piepho H. 1955. Über die Ausrichtung der Schuppenbälge und Schuppen am Schmetterlingsrumpf. Naturwissenschaften 42: 22.

Rawls AS, Guinto JB, Wolff T. 2002. The cadherins Fat and Dachsous regulate dorsal/ventral signaling in the Drosophila eye. Curr Biol 12: 1021-1026.

Shimada Y, Yonemura S, Ohkura H, Strutt D, Uemura T. 2006. Polarized transport of Frizzled along the planar microtubule arrays in Drosophila wing epithelium. Dev Cell 10: 209-222.

Simon MA. 2004. Planar cell polarity in the Drosophila eye is directed by graded Four-jointed and Dachsous expression. Development 131: 6175-6184.

Struhl G, Barbash DA, Lawrence PA. 1997a. Hedgehog acts by distinct gradient and signal relay mechanisms to organise cell type and cell polarity in the Drosophila abdomen. Development 124: 2155-2165.

Struhl G, Barbash DA, Lawrence PA. 1997b. Hedgehog organises the pattern and polarity of epidermal cells in the Drosophila abdomen. Development 124: 2143-2154.

Strutt DI. 2001. Asymmetric localisation of Frizzled and the establishment of cell polarity in the Drosophila wing. Mol Cell 7: 367-375.

Strutt H, Strutt D. 2002. Nonautonomous planar polarity patterning in Drosophila: dishevelled-independent functions of frizzled. Dev Cell 3: 851-863.

Strutt D, Johnson R, Cooper K, Bray S. 2002. Asymmetric localisation of Frizzled and the determination of Notch-dependent cell fate in the Drosophila eye. Curr Biol 12: 813-824.

Strutt H, Mundy J, Hofstra K, Strutt D. 2004. Cleavage and secretion is not required for Four-jointed function in Drosophila patterning. Development 131: 881-890.

Stumpf HF. 1966. Über gefälleabhängige Bildungen des Insektensegmentes. J Insect Physiol 12: 601-617.

Stumpf HF. 1968. Further studies on gradient-dependent diversification in pupal cuticle of Galleria mellonella. J Exp Biol 49: 49-60.

Tomlinson A, Struhl G. 1999. Decoding vectorial information from a gradient: Sequential roles of the receptors Frizzled and Notch in establishing planar polarity in the Drosophila eye. Development 126: 5725-5738.

Tomlinson A, Strapps WR, Heemskerk J. 1997. Linking Frizzled and Wnt signaling in Drosophila development Development 124: 4515-4521.

Tree DRP, Shulman JM, Rousset R, Scott MP, Gubb D, Axelrod JD. 2002. Prickle mediates feedback amplification to generate asymmetric planar cell polarity signalling. Cell 109: 371-381.

Villano JL, Katz FN. 1995. four-jointed is required for intermediate growth in the proximal-distal axis in Drosophila. Development 121: 2767-2777.

Vinson CR, Adler PN. 1987. Directional non-cell autonomy and the transmission of polarity information by the frizzled gene of Drosophila. Nature 329: 549-551. 
Vinson CR, Conover S, Adler PN. 1989. A Drosophila tissue polarity locus encodes a protein containing seven potential transmembrane domains. Nature 338: 262-264.

Waddington CH. 1943. The development of some "leg genes" in Drosophila. J Genet 45: 29-43.

Wehrli M, Tomlinson A. 1998. Independent regulation of anterior/posterior and equatorial/polar polarity in the Drosophila eye; evidence for the involvement of Wnt signaling in the equatorial/polar axis. Development 125: $1421-1432$.

Wigglesworth VB. 1940. Local and general factors in the development of "pattern" in Rhodnius prolixus (hemiptera). J Exp Biol 17: 180-200.

Wright DA, Lawrence PA. 1981. Regeneration of segment boundaries in Oncopeltus: Cell lineage. Dev Biol 85: $328-333$.

Yang C-H, Simon MA, McNeill H. 1999. mirror controls planar polarity and equator formation through repression of fringe expression and through control of cell affinities. Development 126: 5857-5866.
Gradients and the Specification of Planar Polarity

Yang C-H, Axelrod JD, Simon MA. 2002. Regulation of Frizzled by Fat-like cadherins during planar polarity signalling in the Drosophila compound eye. Cell 108: 675-688.

Zallen JA. 2007. Planar polarity and tissue morphogenesis. Cell 129: 1051-1063.

Zeidler MP, Perrimon N, Strutt DI. 1999a. Polarity determination in the Drosophila eye: A novel role for Unpaired and JAK/STAT signalling. Genes Dev 13: 1342-1353.

Zeidler MP, Perrimon N, Strutt DI. 1999b. The four-jointed gene is required in the Drosophila eye for ommatidial polarity specification. Curr Biol 9: 1363-1372.

Zeidler MP, Perrimon N, Strutt DI. 2000. Multiple roles for four-jointed in planar polarity and limb patterning. Dev Biol 228: 181-196.

Zheng L, Zhang J, Carthew RW. 1995. frizzled regulates mirror-symmetric pattern formation in the Drosophila eye. Development 121: 3045-3055. 


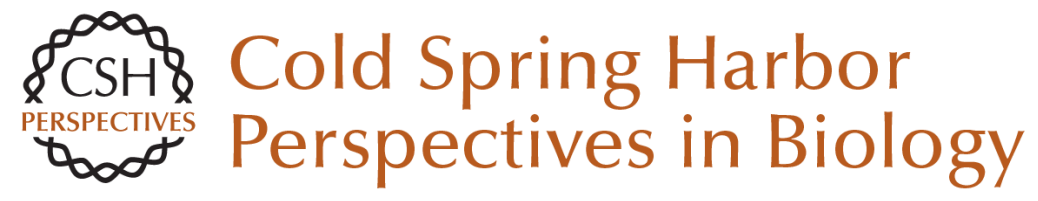

\section{Gradients and the Specification of Planar Polarity in the Insect Cuticle}

David Strutt

Cold Spring Harb Perspect Biol 2009; doi: 10.1101/cshperspect.a000489 originally published online July 15, 2009

\section{Subject Collection Generation and Interpretation of Morphogen Gradients}

Regulation of Organ Growth by Morphogen Gradients

Gerald Schwank and Konrad Basler

Signaling Gradients during Paraxial Mesoderm

Development Alexander Aulehla and Olivier Pourquié

Morphogen Gradient Formation

Ortrud Wartlick, Anna Kicheva and Marcos

González-Gaitán

Nodal Morphogens

Alexander F. Schier

Gradients and the Specification of Planar Polarity

in the Insect Cuticle

David Strutt

Vertebrate Limb Development: Moving from

Classical Morphogen Gradients to an Integrated

4-Dimensional Patterning System Jean-Denis Bénazet and Rolf Zeller

Establishing and Interpreting Graded Sonic

Hedgehog Signaling during Vertebrate Neural

Tube Patterning: The Role of Negative Feedback Vanessa Ribes and James Briscoe

Systems Biology of the Self-regulating

Morphogenetic Gradient of the Xenopus Gastrula Jean-Louis Plouhinec and E. M. De Robertis
Gradients in Planarian Regeneration and Homeostasis

Teresa Adell, Francesc Cebrià and Emili Saló

Shaping Morphogen Gradients by Proteoglycans Dong Yan and Xinhua Lin

Forming Patterns in Development without Morphogen Gradients: Scattered Differentiation and Sorting Out

Robert R. Kay and Christopher R.L. Thompson

Robust Generation and Decoding of Morphogen Gradients

Naama Barkai and Ben-Zion Shilo

Models for the Generation and Interpretation of

Gradients

Hans Meinhardt

Graded Dorsal and Differential Gene Regulation in the Drosophila Embryo

Gregory T. Reeves and Angelike Stathopoulos

Chemical Gradients and Chemotropism in Yeast Robert A. Arkowitz

Gradients in the Brain: The Control of the Development of Form and Function in the Cerebral Cortex

Stephen N. Sansom and Frederick J. Livesey

For additional articles in this collection, see http://cshperspectives.cshlp.org/cgi/collection/

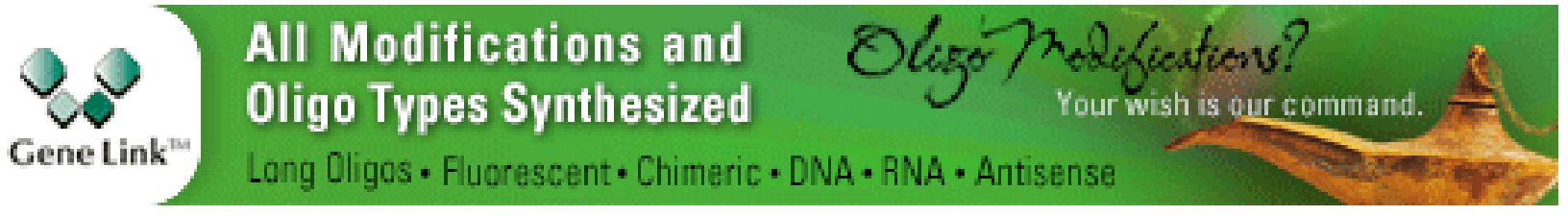


For additional articles in this collection, see http://cshperspectives.cshlp.org/cgi/collection/

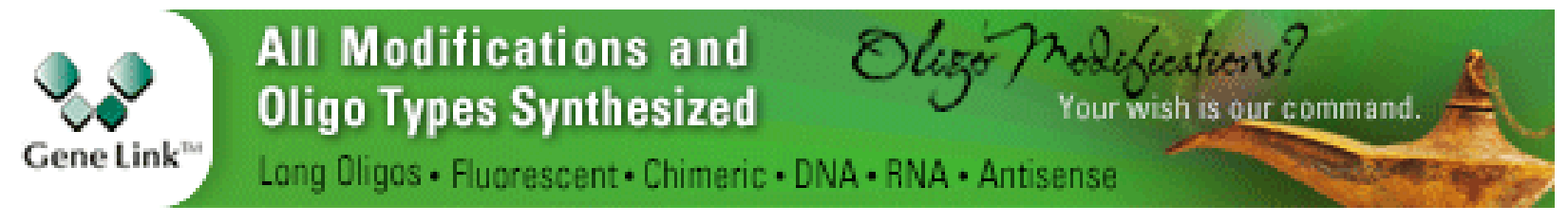

Copyright @ 2009 Cold Spring Harbor Laboratory Press; all rights reserved 